\title{
Perancangan Produk Waistbag dengan Menggunakan Metode Quality Function Deployment (QFD)
}

\author{
Saeful Nurochim*, Asep Nana Rukmana \\ Prodi Teknik Industri, Fakultas Teknik, Universitas Islam Bandung, \\ Indonesia.
}

*efulec@gmail.com, an.rukmana@gmail.com

\begin{abstract}
Product design is a stage in the process of making products based on certain shapes, sizes, and colors. Industrial Home industry is a company engaged in the bag manufacturing industry that has its own product brand, Kaboa. The problem with this is that Kaboa waistbag products have experienced a decline in sales by the significance associated with several problems, namely (1) There are no new models or innovations in Kaboa waistbag products, (2). The objectives of this study are (1) To identify the needs and demands of customers who are priorities and prove to be a variable in the quality of waistbag product designs, (2) Make waistbag product designs according to customer desires and needs to be able to meet customer demand and search. In this study, the method used to develop and request waistbag products to suit customer needs is the Quality Function Deployment (QFD) method. The parameters used in the Kaboa waistbag product design process are 13 quality variables used as references. The best alternative product design options are products made from condura fabric with the cheapest production costs, good quality, strong and durable, with patterned colors according to the consumer and the company's target market with the company's ability.
\end{abstract}

Keywords: Product Design, Quality Function Deployment (QFD), Waistbag.

\begin{abstract}
Abstrak. Perancangan produk merupakan tahapan dalam proses menciptakan sebuah produk berdasarkan model bentuk, ukuran, dan warna tertentu. Home industri Kindustries merupakan perusahaan yang bergerak dibidang industri pembuatan tas yang memiliki brand produk sendiri yaitu Kaboa. Permasalahan yang dihadapi adalah produk waistbag Kaboa telah mengalami penurunan penjualan secara signifikan yang disebabkan beberapa permasalahan yaitu (1) Belum banyaknya model atau inovasi baru pada produk waistbag Kaboa, (2) Pangsa pasar sempit yang hanya di fokuskan kepada kalangan orang yang senang melakukan kegiatan outdoor. Tujuan pada penelitian ini adalah (1) Mengidentifikasi kebutuhan dan keinginan pelanggan yang menjadi prioritas dan menerjemahkannya menjadi variabel kualitas rancangan produk waistbag, (2) Membuat usulan rancangan produk waistbag sesuai keinginan dan kebutuhan pelanggan untuk dapat memenuhi kebutuhan pelanggan dan upaya memperluas pasar untuk meningkatkan penjualan. Dalam penelitian ini, metode yang digunakan untuk mengembangkan dan merancang produk waistbag agar sesuai kebutuhan dengan keinginan pelanggan adalah metode Quality Function Deployment (QFD). Parameter yang digunakan dalam proses desain produk waistbag yaitu berupa 13 variabel kualitas yang digunakan sebagai acuan. Alternatif desain produk pilihan terbaik rancangan produk berbahan kain condura dengan biaya produksi paling murah, berkualitas baik, kuat dan tahan lama, dengan warna bermotif sesuai penilaian konsumen dan target pasar perusahaan serta kemampuan perusahaan.
\end{abstract}

Kata Kunci: Desain Produk, Quality Function Deployment (QFD), Waistbag. 


\section{A. Pendahuluan}

Perancangan produk merupakan tahapan dalam proses menciptakan sebuah produk berdasarkan model bentuk, ukuran, dan warna tertentu. Produk yang diciptakan memiliki nilai jual dan kegunaan untuk konsumen pada pasar penjualan yang di targetkan. Seiring perjalanan waktu konsumen dapat saja berpindah atau mengonsumsi produk lain maka dari itu perusahaan harus dapat mempertahankan konsumen dalam persaingan pasar. Upaya yang dapat dilakukan salah satunya dengan memenuhi kebutuhan dan keinginan konsumen serta peningkatan kualitas pada produk yang dihasilkan. Perusahaan yang menjadi tempat penelitian yaitu home industri Kindustries bertempat di Jl. Setia Graha Raya No.61 Cipaganti Graha Ciwastra. Home industri Kindustries merupakan perusahaan yang bergerak dibidang industri pembuatan pakaian, tas, sepatu, topi, baju, dan dompet. Home industri Kindustries memilki brand produk sendiri yaitu Kaboa. Home industri Kindustries yang bertempat di Jl. Setia Graha Raya No.61 Cipaganti Graha Ciwastra merupakan pusat pembuatan tas untuk penjualan brand Kaboa. Terdapat 3 jenis tas yang diproduksi yaitu Drybag (tas anti air), Backpack Standard (tas punggung), dan Waistbag (tas pinggang). Produk waistbag merupakan produk baru yang exclusive diproduksi Kindustries. Pertama kali di luncurkan pada tahun 2016, dengan target untuk memenuhi permintaan pasar dan kebutuhan konsumen akan fashion tas berukuran kecil sampai sedang guna membawa barang-barang pribadi untuk bepergian mengendarai kendaraan, mendaki gunung, dan kegiatan outdoor lainnya. Dari sisi permintaan dan penjualan produk waistbag, memiliki permintaan dan penjualan yang cukup tinggi karena pada saat masa peluncuran pertama di tahun 2016 menjadi salah satu item yang laris di antara produk Kaboa buatan Kindustries lainnya.

Namun demikian mulai tahun 2017 sampai saat ini produk waistbag telah mengalami penurunan penjualan yang signifikan bila dibandingkan dengan dengan saat masa peluncuran pertama di tahun 2016. Hal yang menyebabkan penurunan daya beli waistbag adalah permasalahan pertama yaitu belum banyaknya model atau inovasi baru pada produk waistbag Kaboa. Waistbag Kaboa sampai saat ini baru terdapat 1 model saja. Permasalahan kedua yaitu pangsa pasar yang sempit, saat ini hanya di fokuskan kepada kalangan orang yang senang melakukan kegiatan outdoor seperti bersepeda, motor trail, mendaki gunung, off road dari anak muda hingga orang tua. Terdapat keinginan pemilik usaha untuk mengembangkan produk waistbag Kaboa dapat menjadi lebih modern dan inovatif untuk membidik pangsa pasar yang lebih luas. Salah satu metode yang dapat digunakan untuk mengembangkan dan merancang produk waistbag agar sesuai kebutuhan dengan keinginan pelanggan adalah metode Quality Function Deployment (QFD). QFD adalah metode terstuktur yang digunakan dalam proses perencanaan dan pengembangan produk untuk menetapkan spesifikasi kebutuhan dan keinginan pelanggan, serta mengevaluasi suatu produk dalam memenuhi kebutuhan dan keinginan pelanggan, serta mengevaluasi dengan sistematis kapabilitas suatu produk atau jasa dalam memenuhi kebutuhan dan keinginan pelanggan (Cohen, 1995).

Dengan penelitian ini, diharapkan dapat memberikan masukan berupa usulan rancangan waistbag yang inovatif, berkualitas, dan menjadi produk yang lebih bersaing di pasaran. Sehingga penjualan waistbag home industri Kindustries dapat berkembang dan maju lagi seperti kondisi sebelumnya.

\section{B. Landasan Teori}

Definisi kualitas produk atau jasa berpusat pada upaya pemenuhan kebutuhan dan keinginan pelanggan serta ketepatan penyampaiannya untuk mengimbangi harapan pelanggan. Kualitas produk atau jasa adalah tingkat keunggulan yang diharapkan dan pengendalian atas tingkat keunggulan tersebut untuk memenuhi keinginan pelanggan. Dengan kata lain ada dua faktor utama yang mempengaruhi yaitu expected service dan preceived service. Apabila yang diterima atau dirasakan (preceived service) sesuai dengan harapan, maka kualias terhadap produk atau jasa dipersepsikan baik atau memuaskan. Jika yang diterima melampaui harapan pelanggan, maka kualitas produk atau jasa dipersepsikan sebagai kualitas yang ideal. Sebaliknya, jika yang diterima lebih rendah dari pada yang diharapkan, maka kualitas produk atau jasa dipersepsikan buruk. Dengan demikian baik buruknya kualitas produk atau jasa tergantung pada kemampuan 
penyedia jasa dalam memenuhi harapan pelanggannya secara konsisten (Tjiptono, 2012, h.157). Garvin (1987) mendefinisikan delapan dimensi yang dapat digunakan untuk menganalisis karakteristik kualitas produk, yaitu sebagai berikut (Nasution, 2001):

1. Performa (performance) berkaitan dengan aspek fungsional dari produk dan merupakan produk.

2. Fitur (features) merupakan aspek kedua dari performa yang menambah fungsi dasar, berkaitan dengan pilihan pilihan dan pengembangannya

3. Keandalan (reability) berkaitan dengan kemungkinan suatu produk berfungsi secara berhasil dalam periode waktu tertentu dan di bawah kondisi tertentu.

4. Konformitas (conformance) berkaitan dengan tingkat kesesuaian produk terhadap spesifikasi yang telah ditetapkan sebelumnya berdasarkan keinginan pelanggan.

5. Daya tahan (Durability) merupakan ukuran masa pakai suatu produk. Karakteristik ini berkaitan dengan daya tahan dari suatu produk.

6. Kemampuan pelayanan (service ability) merupakan karakteristik yang berkaitan dengan kecepatan/kesopanan, kompetensi, kemudahan, serta akurasi dalam perbaikan.

7. Estetika (aesthetics) merupakan karakteristik mengenai keindahan yang bersifat subyektif sehingga berkaitan dengan pertimbangan pribadi dan refleksi dari preferensi atau pilihan individual.

8. Kualitas yang dipersepsikan (perceived quality) bersifat subyektif, berkaitan dengan perasaan pelanggan dalam mengkonsumsi produk, seperti meningkatkan harga diri.

Populasi adalah wilayah generalisasi yang terdiri atas obyek/subyek yang mempunyai kualitas dan karakteristik tertentu yang ditetapkan oleh peneliti untuk dipelajari dan kemudian ditarik kesimpulannya (Sugiyono, 2009).

Pengambilan sampel adalah proses memilih sejumlah elemen secukupnya dari populasi, sehingga penelitian terhadap sampel dan pemahaman tentang sifat atau karakteristiknya akan membuat kita dapat menggeneralisasikan sifat atau karakteristik tersebut pada elemen populasi (Noor, 2011).

Kuesioner merupakan teknik pengumpulan data yang dilakukan dengan cara memberi seperangkat pertanyaan atau pernyataan tertulis kepada responden untuk dijawabnya. Kuesioner merupakan teknik pengumpulan data yang efisien bila peneliti tahu dengan pasti variabel yang akan diukur dan tahu apa yang bisa diharapkan dari responden. Selain itu, kuesioner juga cocok digunakan bila jumlah responden cukup besar dan tersebar diwilayah yang luas (Noor, 2011).

QFD (Quality Function Deployment) adalah metode terstuktur yang digunakan dalam proses perencanaan dan pengembangan produk untuk menetapkan spesifikasi kebutuhan dan keinginan pelanggan, serta mengevaluasi suatu produk dalam memenuhi kebutuhan dan keinginan pelanggan, serta mengevaluasi dengan sistematis kapabilitas suatu produk atau jasa dalam memenuhi kebutuhan dan keinginan pelanggan (Cohen, 1995).

QFD juga merupakan praktik menuju perbaikan proses yang dapat memungkinkan organisasi untuk melampaui harapan pelanggannya. QFD sendiri terdiri atas beberapa aktivitas berikut (Tjiptono dan Diana, 2003):

1. Penjabaran persyaratan pelanggan (kebutuhan akan kualitas).

2. Penjabaran karakteristik kualitas yang dapat diukur.

3. Penentuan hubungan antara kebutuhan kualitas dan karakteristik.

4. Penetapan nilai-nilai berdasarkan angka tertentu terhadap masing-masing karakteristik kualitas.

5. Penyatuan karakteristik kualitas ke dalam produk.

6. Perancangan, produksi, dan pengendalian kualitas produk.

Alat yang digunakan untuk menggunakan struktur QFD adalah matriks berbentuk rumah yang disebut House of Quality (HOQ). Bentuk dan keterangan setiap bagian matriks HOQ dapat dilihat pada Gambar 1. 


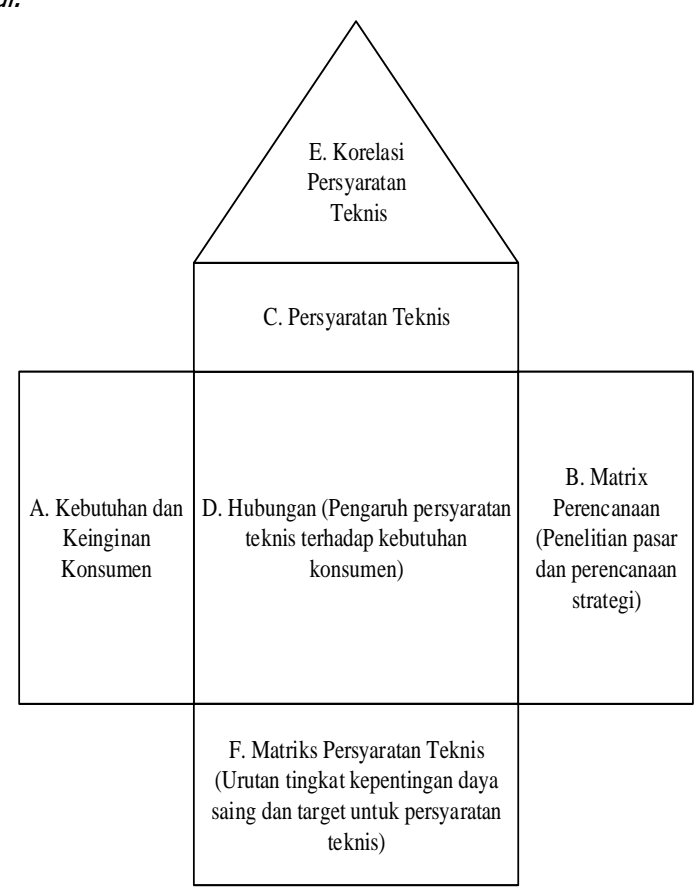

Gambar 1. House of Quality (Cohen: 1995)

\section{Hasil Penelitian dan Pembahasan}

Identifikasi kebutuhan dan keinginan konsumen ini yaitu mengemukakan suara konsumen mengenai desain produk waistbag, adapun alat yang digunakan untuk mengidentifikasi kebutuhan dan keinginan konsumen yaitu menggunakan kuesioner terbuka, kuesioner tertutup, kuesioner pretest dan melakukan penyebaran kuesioner sebenarnya serta melakukuan wawancara terhadap pihak internal perusahaan.

Hasil penyebaran kuesioner terbuka maka dihasilkan data dari variabel karakteristik kebutuhan dan keinginan konsumen tersebut yang selanjutnya dikelompokan kedalam kategori dimensi kualitas produk. Setelah melakukan pengkategorian dimensi kualitas produk, maka didapatkan hasil dari identifikasi kebutuhan dan keinginan konsumen yang menjelaskan tentang variabel-variabel apa saja yang berhubungan dengan kebutuhan dan keinginan konsumen. Identifikasi untuk variabel kebutuhan dan keinginan konsumen dapat dilihat pada Tabel 1 .

Tabel 1. Identifikasi Kebutuhan dan Keinginan Konsumen

\begin{tabular}{|c|c|c|}
\hline No & Variabel Kualitas & Dimensi \\
\hline 1 & Terdapat saku dibagian luar & Features \\
\hline 2 & Berukuran ideal & Performance \\
\hline 3 & Desain trendy dan bermotif menarik & \multirow{2}{*}{ Aesthetics } \\
\hline 4 & Bahan yang digunakan tebal, halus, dan tidak mudah melar & \multirow{2}{*}{ Conformance } \\
\hline 5 & Hasil penjahitan waistbag bagus dan rapih & \\
\hline
\end{tabular}


Lanjutan Tabel 1. Identifikasi Kebutuhan dan Keinginan Konsumen

\begin{tabular}{|c|c|c|}
\hline No & Variabel Kualitas & Dimensi \\
\hline 6 & Bahan yang digunakan kuat dan awet tahan lama & \multirow{3}{*}{ Durability } \\
\hline 7 & Warna bahan awet tidak mudah pudar & \\
\hline 8 & Resleting berkualitas bagus dan awet & \\
\hline 9 & Tidak tembus air & \multirow{3}{*}{ Performance } \\
\hline 10 & Waistbag bisa dijadikan tas selendang & \\
\hline 11 & Tali waistbag mudah diatur/distel & \\
\hline 12 & $\begin{array}{l}\text { Harga yang dikeluarkan sebanding dengan kualitas } \\
\text { waistbagnya }\end{array}$ & $\begin{array}{l}\text { Perceived } \\
\text { Quality }\end{array}$ \\
\hline 13 & $\begin{array}{c}\text { Waistbag nyaman dan aman digunakan untuk membawa } \\
\text { barang pribadi }\end{array}$ & Reability \\
\hline
\end{tabular}

Sumber : Data Penelitian yang Sudah Diolah, 2019.

Berdasarkan hasil perhitungan, dapat dilihat untuk $\mathrm{r}$ hitung sebesar 0,646 sedangkan untuk nilai $r$ tabel menurut tabel angka kritik untuk N-2 yaitu 30-2 = 28 dan taraf signifikan 5\% $=0,05$ maka nilai $r$ tabel yaitu 0,361 . Karena $r$ hitung $\geq \mathrm{r}$ tabel $=0,646 \geq 0,3610$, maka pernyataan dinyatakan Valid. Karena pernyataan tersebut valid maka dapat dilakukan pengolahan selanjutnya. Adapun rekapitulasi dari product moment dapat dilihat pada Tabel 2.

Tabel 2. Rekapitulasi Nilai Korelasi Product Moment Mengenai Tingkat Kepentingan Konsumen dan Penilaian Konsumen

\begin{tabular}{|c|c|c|c|c|c|c|c|}
\hline \multirow[b]{2}{*}{ No } & \multirow[b]{2}{*}{ Pernyataan } & \multirow[b]{2}{*}{ r Tabel } & \multicolumn{4}{|c|}{ Nilai Kolerasi Hasil Kuesioner Pretest } & \multirow[b]{2}{*}{ Keterangan } \\
\hline & & & $\begin{array}{l}\text { r Hitung } \\
\text { (Tingkat } \\
\text { Kepentingan } \\
\text { Konsumen) }\end{array}$ & $\begin{array}{l}\text { r Hitung } \\
\text { (Penilaian } \\
\text { Produk } \\
\text { Kaboa) }\end{array}$ & $\begin{array}{c}\text { r Hitung } \\
\text { (Penilaian } \\
\text { Produk } \\
\text { Pesaing } \\
\text { QuikSilver) }\end{array}$ & $\begin{array}{l}\text { r Hitung } \\
\text { (Penilaia } \\
\text { nProduk } \\
\text { Pesaing } \\
\text { Cosmic) }\end{array}$ & \\
\hline 1 & $\begin{array}{l}\text { Terdapat saku } \\
\text { dibagian luar }\end{array}$ & 0,361 & 0,646 & 0,791 & 0,856 & 0,682 & Valid \\
\hline 2 & Berukuran ideal & 0,361 & 0,797 & 0,767 & 0,762 & 0,777 & Valid \\
\hline 3 & $\begin{array}{c}\text { Desain trendy } \\
\text { dan bermotif } \\
\text { menarik }\end{array}$ & 0,361 & 0,695 & 0,706 & 0,758 & 0,667 & Valid \\
\hline 4 & $\begin{array}{c}\text { Bahan yang } \\
\text { digunakan tebal, } \\
\text { halus, dan tidak } \\
\text { mudah melar }\end{array}$ & 0,361 & 0,704 & 0,783 & 0,790 & 0,718 & Valid \\
\hline 5 & $\begin{array}{c}\text { Hasil penjahitan } \\
\text { waistbag bagus } \\
\text { dan rapih }\end{array}$ & 0,361 & 0,722 & 0,790 & 0,790 & 0,567 & Valid \\
\hline 6 & $\begin{array}{c}\text { Bahan yang } \\
\text { digunakan kuat } \\
\text { dan awet tahan } \\
\text { lama }\end{array}$ & 0,361 & 0,748 & 0,687 & 0,799 & 0,483 & Valid \\
\hline
\end{tabular}


6 | Saeful Nurochim, et al.

Lanjutan Tabel 2. Rekapitulasi Nilai Korelasi Product Moment Mengenai Tingkat Kepentingan Konsumen dan Penilaian Konsumen

\begin{tabular}{|c|c|c|c|c|c|c|c|}
\hline \multirow[b]{2}{*}{ No } & \multirow[b]{2}{*}{ Pernyataan } & \multirow[b]{2}{*}{ r Tabel } & \multicolumn{4}{|c|}{ Nilai Kolerasi Hasil Kuesioner Pretest } & \multirow[b]{2}{*}{ Keterangan } \\
\hline & & & $\begin{array}{l}\text { r Hitung } \\
\text { (Tingkat } \\
\text { Kepentingan } \\
\text { Konsumen) }\end{array}$ & $\begin{array}{l}\text { r Hitung } \\
\text { (Penilaian } \\
\text { Produk } \\
\text { Kaboa) }\end{array}$ & $\begin{array}{c}\text { r Hitung } \\
\text { (Penilaian } \\
\text { Produk } \\
\text { Pesaing } \\
\text { QuikSilver) }\end{array}$ & $\begin{array}{c}\text { r Hitung } \\
\text { (Penilai } \\
\text { anProd } \\
\text { uk } \\
\text { Pesaing } \\
\text { Cosmic) }\end{array}$ & \\
\hline 7 & $\begin{array}{c}\text { Warna bahan } \\
\text { awet tidak mudah } \\
\text { pudar }\end{array}$ & 0,361 & 0,916 & 0,706 & 0,758 & 0,506 & Valid \\
\hline 8 & $\begin{array}{c}\text { Resleting } \\
\text { berkualitas bagus } \\
\text { dan awet }\end{array}$ & 0,361 & 0,897 & 0,783 & 0,790 & 0,777 & Valid \\
\hline 9 & Tidak tembus air & 0,361 & 0,795 & 0,790 & 0,779 & 0,452 & Valid \\
\hline 10 & $\begin{array}{l}\text { Waistbag bisa } \\
\text { dijadikan tas } \\
\text { selendang }\end{array}$ & 0,361 & 0,764 & 0,729 & 0,724 & 0,694 & Valid \\
\hline 11 & $\begin{array}{c}\text { Tali waistbag } \\
\text { mudah } \\
\text { diatur/distel }\end{array}$ & 0,361 & 0,803 & 0,778 & 0,758 & 0,725 & Valid \\
\hline 12 & $\begin{array}{c}\text { Harga yang } \\
\text { dikeluarkan } \\
\text { sebanding dengan } \\
\text { kualitas } \\
\text { waistbagnya }\end{array}$ & 0,361 & 0,809 & 0,791 & 0,766 & 0,691 & Valid \\
\hline 13 & $\begin{array}{l}\text { Waistbag nyaman } \\
\text { dan aman } \\
\text { digunakan untuk } \\
\text { membawa barang }\end{array}$ & 0,361 & 0,728 & 0,783 & 0,686 & 0,613 & Valid \\
\hline
\end{tabular}

Sumber : Data Penelitian yang Sudah Diolah, 2019

Uji Realibilitas dilakukan dengan menggunakan software SPSS Ver 17.0 Nilai koefisien reliabilitas (Alpha Cronbach) berkisar antara 0 hingga 1. Makin besar nilai koefisiennya maka makin besar keandalan alat ukur yang digunakan. Jika nilai koefisien reliabilitas (Alpha Cronbach) $\alpha \geq 0,7$ maka ini menunjukkan bahwa alat ukur yang digunakan sudah handal. Adapun perhitungan uji realibilitas dengan menggunakan software SPSS Ver 17.0 dapat dilihat pada Tabel 3.

Tabel 3. Hasil Uji Reliabilitas Dengan Software SPSS Ver 17.0 Mengenai Tingkat Kepentingan dan Penilaian Konsumen

\begin{tabular}{|c|c|c|c|c|}
\hline \multirow{2}{*}{$\begin{array}{c}\text { Jenis } \\
\text { Kuesioner }\end{array}$} & $\begin{array}{c}\text { Tingkat } \\
\text { Kepentingan } \\
\text { Konsumen }\end{array}$ & $\begin{array}{c}\text { Penilaian } \\
\text { Konsumen } \\
\text { Terhadap Produk } \\
\text { Waistbag Kaboa }\end{array}$ & $\begin{array}{c}\text { Penilaian Konsumen } \\
\text { Terhadap Produk } \\
\text { Pesaing QuikSilver }\end{array}$ & $\begin{array}{c}\text { Penilaian Konsumen } \\
\text { Terhadap Produk } \\
\text { Pesaing Cosmic }\end{array}$ \\
\hline $\begin{array}{c}\text { Kuesioner } \\
\text { Tertutup } \\
\text { Pretest }\end{array}$ & 0,942 & 0,937 & 0,940 & 0,878 \\
\hline
\end{tabular}

Sumber : Data Penelitian yang Sudah Diolah, 2019

Berdasarkan hasil rekapitulasi nilai Alpha Cronbach dari Tabel 4.16 diatas dapat dilihat bahwa data harapan konsumen, persepsi produk waistbag Kaboa, dan produk pesaing, nilai alpha Cronbach-nya mendekati 1 atau > 0,7, maka dinyatakan bahwa kuesioner yang digunakan 
dapat diandalkan.

Jumlah sampel adalah jumlah responden berusia remaja-dewasa, pria/wanita berusia 15 hingga 49 tahun pengguna waistbag di kota Bandung. Sampel yang ada merupakan jumlah responden untuk kuesioner sebenarnya. Besarnya populasi menggunakan data populasi jumlah penduduk menurut kelompok umur dan jenis kelamin di Kota Bandung Tahun 2016. Berdasarkan data diatas diketahui jumlah penduduk laki-laki dan perempuan pada kelompok umur 15-19 tahun sebanyak 222.489 jiwa, pada kelompok umur 20-24 tahun sebanyak 259.461 jiwa, pada kelompok umur 25-29 tahun sebanyak 230.114 jiwa, pada kelompok umur 30-34 tahun sebanyak 213.888 jiwa, pada kelompok umur 35-39 tahun sebanyak 197.370 jiwa, pada kelompok umur 40-44 tahun sebanyak 184.806 jiwa, dan pada kelompok umur 45-49 tahun sebanyak 162.490 jiwa.

Kemudian masing-masing data penduduk tersebut di jumlahkan untuk mengetahui jumlah populasi yang ada. Berdasarkan kategori usia 15 sampai 49 tahun berjenis kelamin lakilaki dan perempuan di Kota Bandung didapatkan sebanyak 1.470.618 jiwa. berikut:

Maka penentuan jumlah responden menggunakan rumus Slovin, Umar (2008) sebagai

$$
n=\frac{N}{1+\left(N \times e^{2}\right)}=\frac{1470618}{1+\left(1470618 \times 0.1^{2}\right)}=99,993 \approx 100
$$

Keterangan rumus Slovin, Umar (2008):

$n \quad=$ Jumlah sampel minimal

$N \quad=$ Jumlah populasi penelitian yaitu $1.470 .618 \mathrm{jiwa} /$ orang

$e^{2} \quad=$ margin of error max atau kesalahan maksimum yang dapat di toleransi biasanya sebesar $10 \%$.

Tabel 4. Jumlah Kuesioner

\begin{tabular}{|c|c|c|}
\hline Pelanggan & Jumlah Kuesioner yang Disebar & Jumlah Kuesioner yang Layak \\
\hline Eskternal & 100 & 97 \\
\hline
\end{tabular}

Sumber : Data Penelitian yang Sudah Diolah, 2019

Pada tingkat ketelitian $95 \%$, tingkat kesalahan $10 \%$ dan nilai $Z_{(1-\alpha / 2)}=1,96$, maka sampel minimum yang dibutuhkan pada penelitaian ini sebanyak:

$\mathrm{N} \geq \mathrm{n}^{\prime}, n \geq \frac{Z_{\alpha / 2}^{2} \times p \times q}{(e)^{2}}$

$\mathrm{n}^{\prime}=\frac{(1,96)^{2} \times 0,97 \times 0,03}{(0,1)^{2}}$

$\mathrm{n}^{\prime}=\frac{3,8416 \times 0,97 \times 0,03}{0,01}$

$\mathrm{n}^{\prime}=11,179 \approx 11$

Dari hasil pengumpulan data kuesioner yang telah dilakukan, dan jumlah kuesioner yang sah sebanyak 97 kuesioner, maka data yang dibutuhkan dapat dikatakan cukup karena $\mathrm{N}$ $\geq$ n' $(97 \geq 11)$.

Dalam pembuatan matriks Quality Function Deployment (QFD) terdapat beberapa fase untuk menunjang beberapa informasi dalam pembuatan matriks perancangan yaitu di antaranya:

1. Pengembangan matriks perencanaan produk.

2. Pengembangan matriks perencanaan komponen.

3. Pengembangan matriks perencanaan proses.

4. Pengembangan matriks perencanaan produksi.

Pengembangan matriks perencanaan produk merupakan matriks pertama dalam Quality Function Deployment (QFD). Dimana WHATs ditempatkan di sebelah kiri matrik. WHATs ialah 
8 | Saeful Nurochim, et al.

kondisi yang menggambarkan keuntungan atau objek yang ingin dicapai konsumen. Untuk prioritas WHAT $s$ ditempatkan dibagian kanan matrik. Lalu HOWs ditempatkan dibagian atas pada matrik. HOWs ialah sejumlah respons potensial dari WHATs. Prioritas dari HOWs ditempatkan dibagian bawah rumah kualitas, dimana ini merupakan hasil prinsip rumah kualitas. Hasil pengolahan data fasa 1 yaitu matriks perencanaan produk ditampilkan dalam House of Quality seluruhnya dapat dilihat pada Gambar 2.

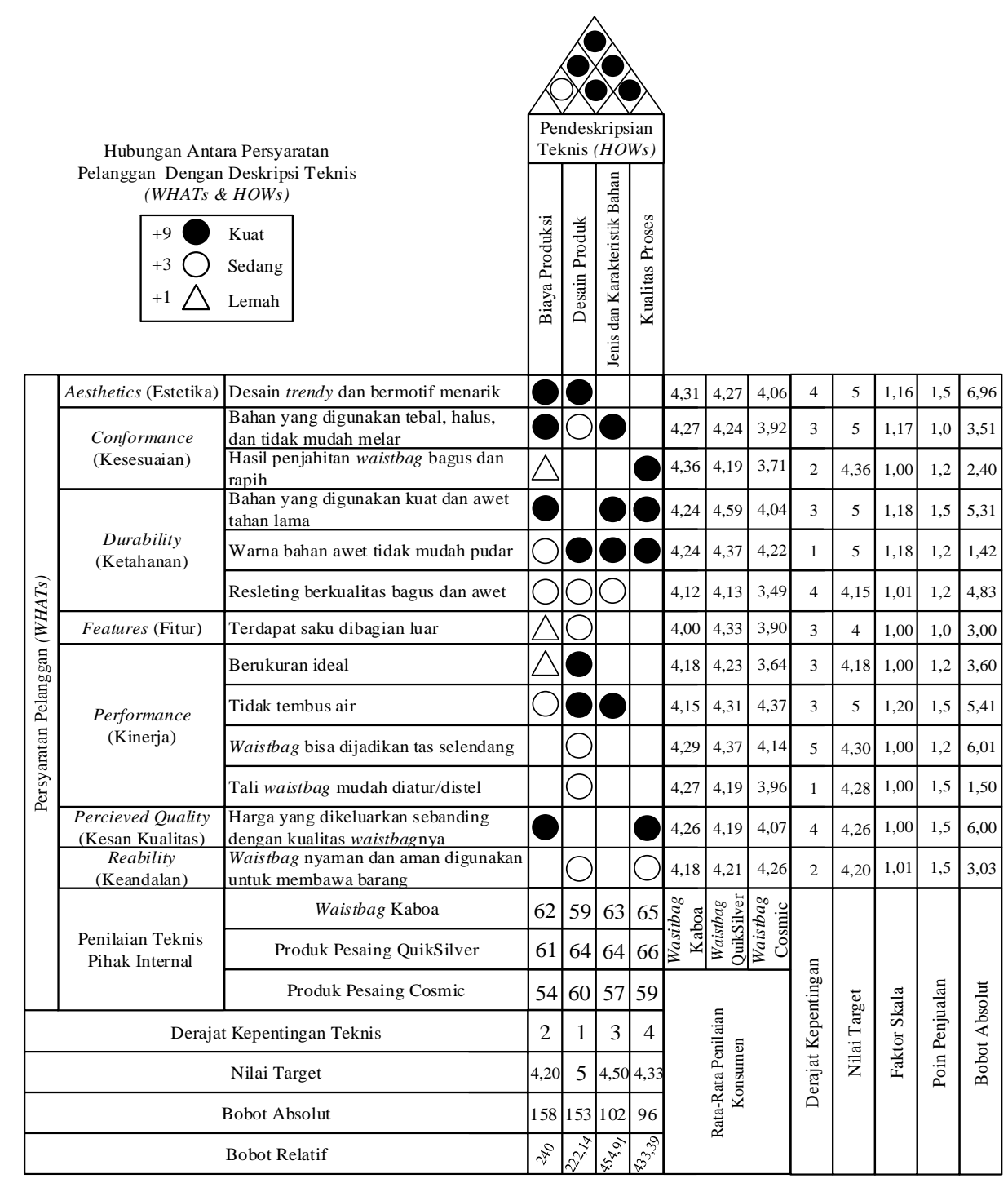

Gambar 2. Matriks Perencanaan Produk (QFD Fasa 1)

Perencanaan komponen merupakan proses pengembangan karakteristik teknik bagi perusahaan yang dihasilkan berdasarkan matriks fasa 1 menjadi lebih detail dalam membentuk karakteristik komponen. Atribut produk membentuk baris matriks dan karakteristik komponen membentuk kolom matriks. Dalam pengembangan matriks perencanaan komponen diperlukan beberapa tahapan untuk menunjang segala informasi yang dibutuhkan. Pertama-tama yaitu pengelompokan atribut-atribut produk karakteristik teknik (Technical Requirement and Target $(W H A T s)$ ) ke dalam karakteristik komponen (Critical Part Requirement (HOWs)) yang dibutuhkan dalam perancangan. Adapun hasil rekapitulasi pengolahan data dalam matriks perencanaan komponen fasa 2 ditunjukan pada Gambar 3. 


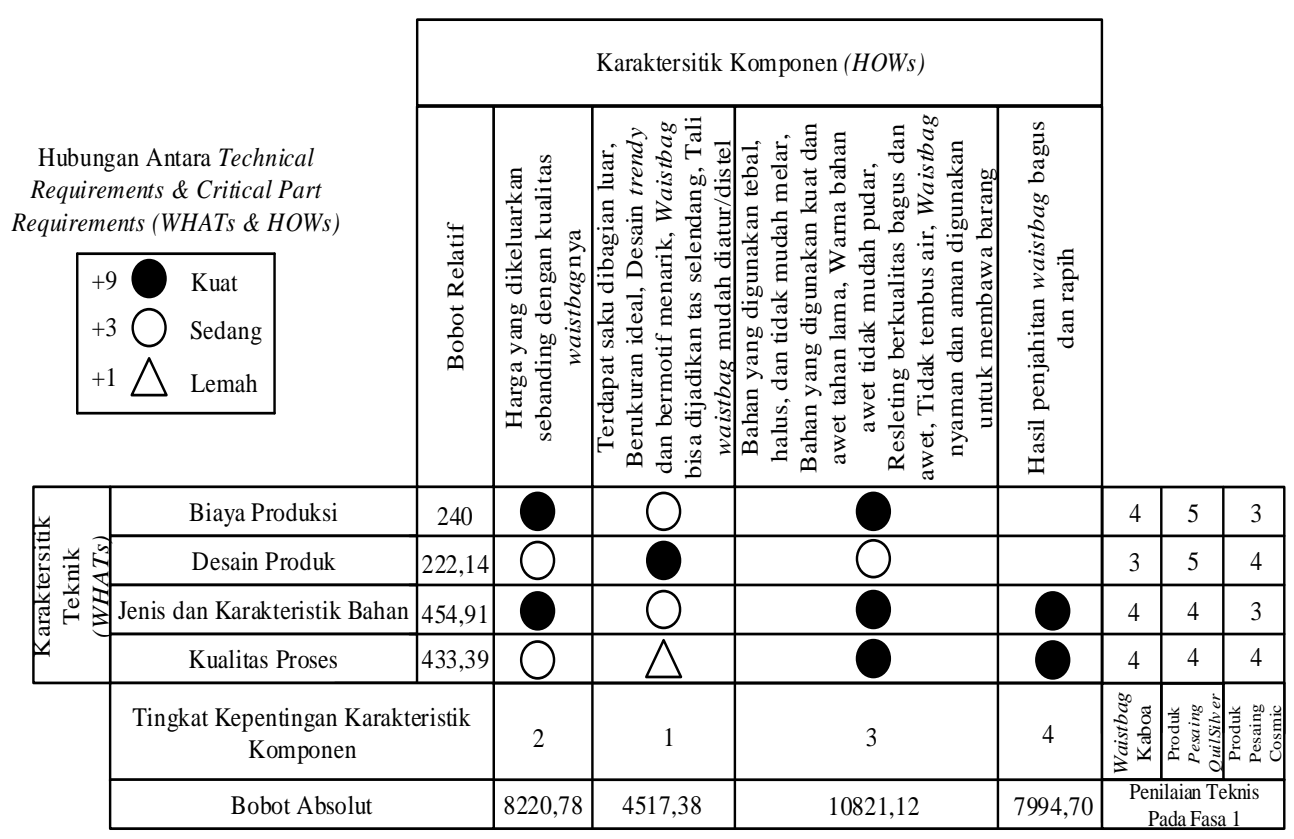

Gambar 3. Matriks Perencanaan Komponen (Hasil QFD Fasa 2)

Berdasarkan hasil dari pengembangan matriks Quality Function Deployment (QFD) fasa 1 dan fasa 2 didapatkan prioritas utama yang harus diperhatikan dalam perancangan produk waistbag Kaboa untuk meningkatkan kualitas dan penjualan produk waistbag Kaboa sesuai dengan kebutuhan dan keinginan konsumen. Setelah karakteristik komponen dikelompokan kedalam karakteristik teknik maka selanjutnya mendeskripsikan karakteristik teknik kedalam paramater teknik yang akan digunakan dalam rancangan produk waistbag Kaboa.
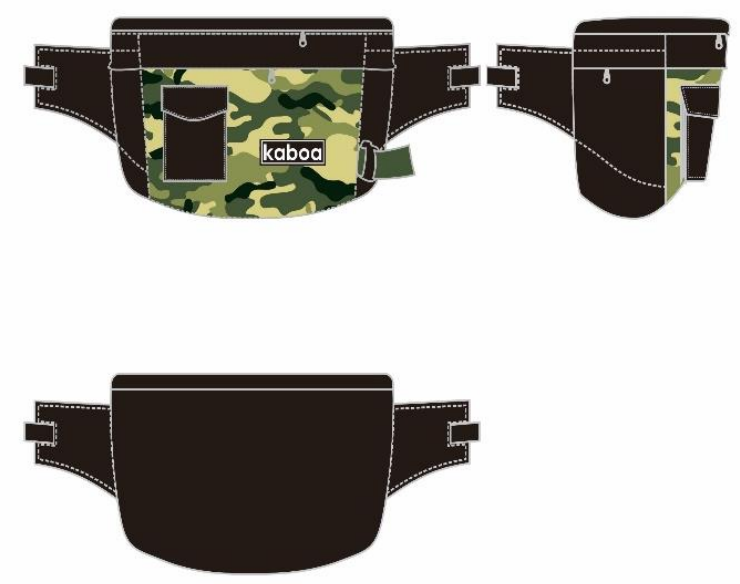

Gambar 4. Alternatif 1 Rancangan Produk Waistbag Kaboa Berdasarkan Parameter Teknik 


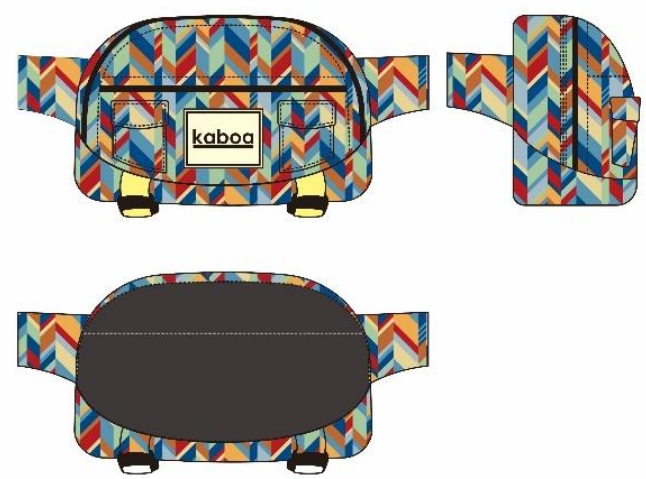

Gambar 5. Alternatif 2 Rancangan Produk Waistbag Kaboa Berdasarkan Parameter Teknik

Adapun perbandingan antara alternatif rancangan produk waisbag Kaboa satu dan dua ditunjukan pada Tabel 5.

Tabel 5. Perbandingan Alternatif Rancangan Produk Waistbag Kaboa

\begin{tabular}{|c|c|c|c|}
\hline No & $\begin{array}{l}\text { Karakteristik } \\
\text { Teknik }\end{array}$ & Alternatif 1 & Alternatif 2 \\
\hline \multirow{15}{*}{1} & \multirow{15}{*}{$\begin{array}{l}\text { Jenis dan } \\
\text { Karakteristik } \\
\text { Bahan }\end{array}$} & Kain Kanvas : $600 Z$ & Kain Condura : KSA32 \\
\hline & & Puring Torin : 420 (Kedap Air) & Puring Torin : 420 (Kedap Air) \\
\hline & & Sablon Plastisol & Sablon PPC \\
\hline & & Sleting : YKK No. 5 & Sleting : YKK No. 5 \\
\hline & & Kepala Sleting : YKK No. 5 & Kepala Sleting : YKK No. 5 \\
\hline & & Tali : FA 3,8 cm & Tali : FA 3,8 cm \\
\hline & & Sling & Sling \\
\hline & & Gesper & Gesper \\
\hline & & Ring Jalan & Ring Jalan \\
\hline & & Slot : DSRE 3,8 Asetal & Slot : DSRE 3,8 Asetal \\
\hline & & Tali Kur & Tali Kur \\
\hline & & Stopper & Stopper \\
\hline & & Jaring Dalam & Jaring Dalam \\
\hline & & Ring Kait Dalam & Ring Kait Dalam \\
\hline & & Tahan air (Water tied) & Tahan air (Water tied) \\
\hline 2 & Biaya Produksi & $\mathrm{Rp} 95.000$ & $\mathrm{Rp} 84.000$ \\
\hline 3 & Kualitas Proses & $\begin{array}{l}\text { Hasil penjahitan bagus dan } \\
\text { rapih }\end{array}$ & $\begin{array}{l}\text { Hasil penjahitan bagus dan } \\
\text { rapih }\end{array}$ \\
\hline \multirow{6}{*}{4} & \multirow{6}{*}{ Desain Produk } & Panjang Atas $34 \mathrm{~cm}$ & Panjang Atas $22 \mathrm{~cm}$ \\
\hline & & Panjang Bawah $22 \mathrm{~cm}$ & Panjang Bawah $34 \mathrm{~cm}$ \\
\hline & & Tinggi $19 \mathrm{~cm}$ & Tinggi $19 \mathrm{~cm}$ \\
\hline & & $\begin{array}{c}\text { Saku luar di bagian depan } \\
\text { sebelah kanan dan dibagian } \\
\text { samping kanan }\end{array}$ & $\begin{array}{l}\text { Saku luar bagian depan } \\
\text { sebelah kiri dan kanan }\end{array}$ \\
\hline & & $\begin{array}{l}\text { Warna dan gambar bermotif } \\
\text { alam }\end{array}$ & $\begin{array}{l}\text { Warna dan gambar bermotif } \\
\text { gradasi warna }\end{array}$ \\
\hline & & Label di dalam dan di luar & Label di dalam dan di luar \\
\hline
\end{tabular}


Lanjutan Tabel 5. Perbandingan Alternatif Rancangan Produk Waistbag Kaboa

\begin{tabular}{|c|c|c|c|}
\hline No & $\begin{array}{c}\text { Karakteristik } \\
\text { Teknik }\end{array}$ & Alternatif 1 & Alternatif 2 \\
\hline \multirow{2}{*}{4} & Desain Produk & Puring Bermotif & Puring Bermotif \\
\cline { 3 - 4 } & & Dapat dijadikan tas selendang & Dapat dijadikan tas selendang \\
\hline
\end{tabular}

Dalam matriks perencanaan proses, karakteristik komponen membentuk baris matriks (WHATs) dan karakteristik proses membentuk kolom matriks (HOWs). Setiap sel matriks menunjukan hubungan potensial diantara karakteristik komponen dengan karakteristik proses, dan mencatatnya dalam sel-sel matriks. Adapun hasil rekapitulasi pengolahan data dalam matriks perencanaan proses fasa 3 ditunjukan pada Gambar 6 .

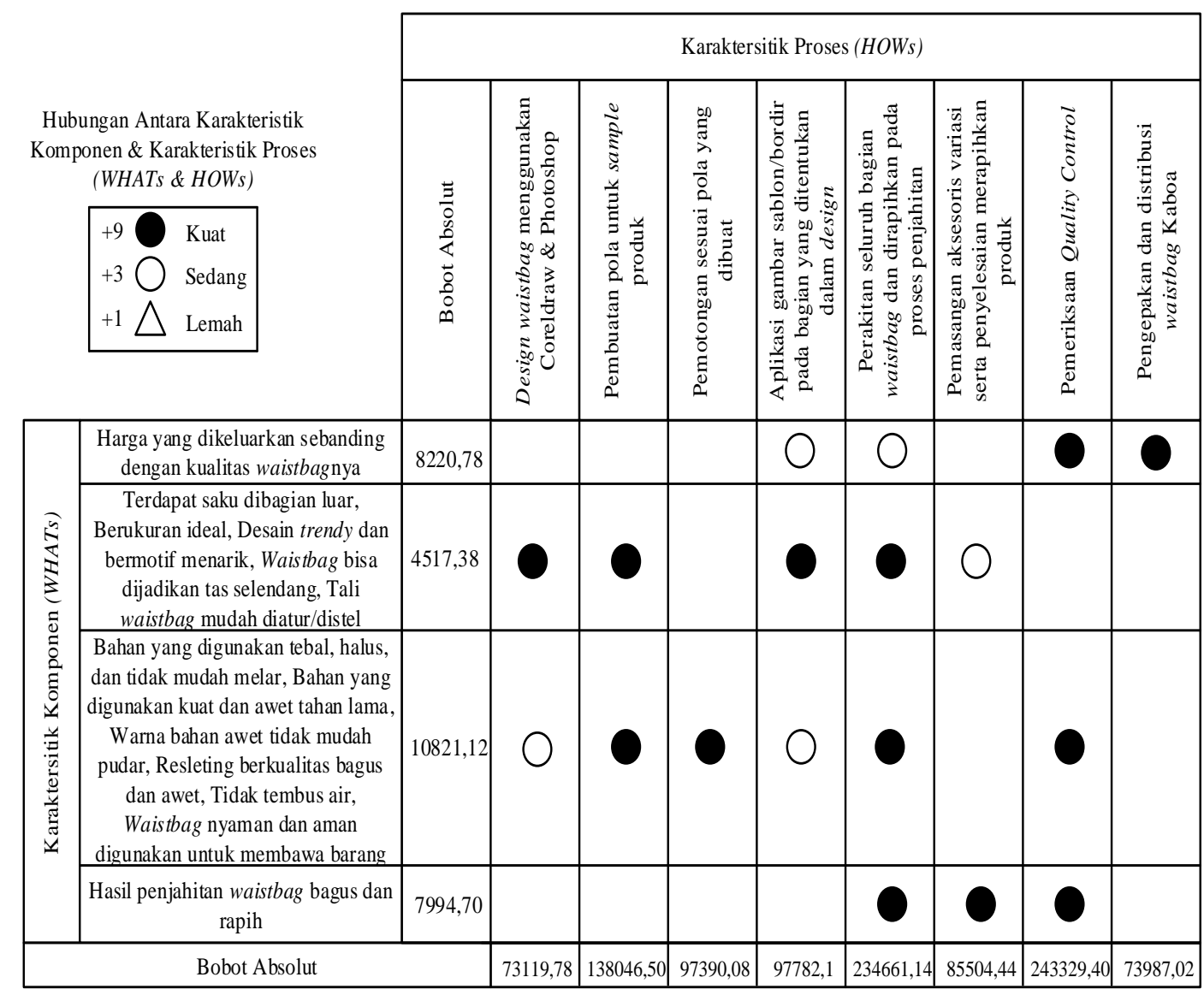

Gambar 6. Matriks Perencanaan Proses (QFD Fasa 3) 


\section{Kesimpulan}

Berdasarkan hasil yang diperoleh pada bab sebelumnya, maka dapat ditarik beberapa kesimpulan dari hasil penelitian yang telah dilakukan antara lain yaitu:

1. Dalam mengidentifikasi kebutuhan dan keinginan pelanggan yang menjadi prioritas dan menerjemahkannya menjadi variabel kualitas untuk meningkatkan kualitas dan daya beli produk waistbag Kaboa, melalui tahap penyebaran kuesioner didapatkan 13 (tiga belas) variabel pernyataan yang sesuai dengan kebutuhan dan keinginan konsumen dan menjadi variabel kualitas perancangan produk waistbag. Selanjutnya dikelompokkan kedalam 4 (empat) pendeskripsian karakteristik adalah yaitu:

- Jenis dan karakteristik bahan yaitu bahan yang digunakan tebal, halus, dan tidak mudah melar, bahan yang digunakan kuat dan awet tahan lama, warna bahan awet tidak mudah pudar, resleting berkualitas bagus dan awet, tidak tembus air, waistbag nyaman dan aman digunakan untuk membawa barang.

- Biaya produksi yaitu harga yang dikeluarkan sebanding dengan kualitas waistbagnya.

- Kualitas proses yaitu hasil penjahitan waistbag bagus dan rapih. Sampai saat ini proses produksi di home industri Kindustries untuk produk Kaboa dan lainnya selalu dilakukan dengan teliti baik dan rapih untuk menghindari komplain dari konsumen dan memperkecil kemungkinan kecacatan hasil produksi home industri Kindustries.

- Desain produk yaitu terdapat saku dibagian luar, berukuran ideal, desain trendy dan bermotif menarik, waistbag bisa dijadikan tas selendang, tali waistbag mudah diatur/distel.

2. Berdasarkan kedua alternatif rancangan desain produk yang telah dibuat, maka alternatif rancangan desain produk terbaik yang dipilih untuk waistbag Kaboa yaitu alternatif kedua, dimana rancangan produk alternatif kedua tersebut memiliki biaya produksi yang lebih rendah dibandingkan dengan alternatif pertama, berkualitas baik, kuat dan tahan lama, dengan warna bermotif yang dapat menarik perhatian dan daya tarik konsumen untuk membeli produk, serta sudah mengaplikasikan teknologi water tied yang membuat waistbag Kaboa tidak tembus air dapat digunakan dalam kondisi kering maupun basah sehingga sesuai dengan kebutuhan dan keinginan konsumen dan sesuai dengan target pasar perusahaan serta kemampuan perusahaan.

\section{E. Saran}

Adapun saran-saran yang dapat disampaikan kepada perusahaan home industri Kindustries, antara lain :

1. Home industri Kindustries sebaiknya lebih dapat membuat inovasi dalam waktu yang lebih cepat mengikuti era perkembangan teknologi dan trend terhadap produk yang dihasilkan dan dapat lebih membaca peluang pasar yang tersedia saat ini maupun dalam kurun waktu yang akan datang agar potensi penjualan dapat tetap bertahan dan bahkan lebih berkembang lagi dari sebelumnya, serta agar dapat mempertahankan konsumen dan menarik perhatian konsumen baru lebih banyak lagi.

2. Hasil penelitian terhadap perancangan produk waistbag Kaboa home industri Kindustries ini dapat bermanfaat bagi perusahaan dalam upaya melakukan peningkatan kualitas produk demi tercapainya kepuasan konsumen dan memperluas pasar untuk meningkatkan penjualan home industri Kindustries. 


\section{Daftar Pustaka}

[1] Adi, P.P., 2017. Perancangan Produk Kantong Sampah Pendaki Menggunakan Metode Quality Function Deployment (QFD). Diploma thesis. Universitas Komputer Indonesia. Tersedia pada: http://elib.unikom.ac.id. [Di Akses: 2 Maret 2018].

[2] Besterfield, D,H, dkk., 2003. Total Quality Management. Third Edition. New Jersey: Prentice Hall International, Inc.

[3]Cohen, L., 1995. Quality Function Deployment: How to Make QFD Work for You. Massachusett. Addison-Wesley Publishing Company.

[4] Garvin, D.A., 1987. MANAGING QUALITY: Competing in the Eight Dimensions of Quality. Harvard Business.

[5] Ghozali, I., 2001. Aplikasi Analisis Multivariate dengan Program SPSS. Semarang. Badan Penerbit Universitas Diponegoro.

[6] Nasution, M.N., 2001. Manajemen Mutu Terpadu. Jakarta. Ghalia Indonesia.

[7] Noor, J., 2011. Metodologi Penelitian: Skripsi, Thesis, Disertasi, dan Karya Ilmiah. Jakarta. Prenada Media.

[8] Setiawan, A., 2014. Perancangan Kantong Kain Belanja dengan Metode Quality Function Deployment. Diploma thesis. Universitas Komputer Indonesia. Tersedia pada: http://elib.unikom.ac.id. [Di Akses: 2 Maret 2018].

[9] Shihab, Q., 2019. Tafsir Al-Qur'an. Dewan Syariah Nasional - Majelis Ulama Indonesia. Tersedia pada: https://tafsirq.com. [Di Akses: 30 Juli 2019].

[10] Sugiyono, Prof, Dr., 2009. Metode Penelitian Kuantitatif, Kualitatif dan R\&D. CV. Alfabeta.

[11] Tjiptono, F., dan Diana, A., 2001. Total Quality Management. Yogyakarta. Andi.

[12] Tjiptono, F., dan Diana, A., 2003. Total Quality Management. Yogyakarta. Andi.

[13] Tjiptono, F., 2012. Service Management: Mewujudkan Layanan Prima (Edisi 2). Yogyakarta. Andi, p.157.

[14] Ulrich, K.T., dan Eppinger, S.D., 2000. Product Design and Development. Boston: Irwin McGraw-Hill Co, pp.14-23.

[15] Umar, H., 2008. Metode Penelitian Untuk Skripsi dan Tesis Bisnis. Jakarta. PT Rajagrafindo Persada.

[16] Wijaya, T., 2011. Manajemen Kualitas Jasa. Jakarta. Indeks. 